\title{
PERMAINAN TRADISIONAL ELENGAN MENINGKATKAN KECEPATAN UNDERWATER RENANG GAYA KUPU-KUPU
}

\author{
Abdul Narlan ${ }^{1}$, Ari Priana ${ }^{2}$, Yuniarti Sani Damayanti ${ }^{3}$ \\ ${ }^{1}$ Pendidikan Jasmani Universitas Siliwangi \\ ${ }^{2}$ Pendidikan Jasmani Universitas Siliwangi \\ 1abdulnarlan@unsil.ac.id, 2aripriana@unsil.ac.id, ${ }^{3}$ yuniartisanidamayanti@gmail.com
}

\begin{abstract}
ABSTRAK
Proses latihan dikombinasikan ke dalam bentuk permainan yang diangkat dari permainan tradisional untuk mengalihkan suasana latihan menjadi menyenangkan. Penelitian yang telah dilaksanakan bertujuan untuk mengetahui pengaruh permainan tradisional elengan terhadap kecepatan underwater renang gaya kupu-kupu pada atlet renang kelompok usia 4 dan kelompok usia 5. Metode penelitian dalam penelitian ini menggunakan metode eksperimen dengan menggunakan model one-group pretest-postest. Menggunakan model one-group pretestpostest dengan harapan hasil perlakuan dapat diketahui lebih akurat karena dapat membandingkan hasil sebelum diberikan perlakuan dengan setelah diberikan perlakuan. Pengujian hipotesis menunjukan bahwa permainan tradisional elengan dapat berpengaruh terhadap kecepatan underwater renang gaya kupu-kupu. Permainan tradisional tidaklah hanya sekedar permainan untuk kesenangan semata, namun secara tidak sadar banyak sekali pembendaharaan gerak yang kita kenali hasil dari bermain dalam permainan tradisional, banyak juga sumbangsih kondisi fisik yang terbentuk dalam tubuh kita hasil dari bermain dalam permainan tradisional.
\end{abstract}

Kata Kunci: Permainan tradisional; elengan; underwater

\begin{abstract}
The training process is combined into a form of game that is lifted from traditional games to divert the atmosphere of the training to be fun. The research that has been done aims to determine the influence of elengan traditional games on the underwater swimming speed of butterfly stroke at the age group 4 and age group 5 athletes. The research method in this study used an experimental method using a one-group pretest-posttest model. Using a one-group pretest-posttest model in the hope that the treatment results can be known more accurately because they can compare the results before being given treatment with after treatment. This shows that the elengan traditional game influences to the underwater speed of butterfly stroke swimming. Traditional games are not just a game for fun, but unconsciously many your motion that we know the result of playing in traditional games, many also contribute physical conditions are formed in our body the result of playing in traditional games.
\end{abstract}

Keywords: Traditional games; elengan; underwater

Dipublikasikan Oleh :

UPT Publikasi dan Pengelolaan Jurnal

Universitas Islam Kalimantan Muhammad Arsyad Al Banjari Banjarmasin 


\section{PENDAHULUAN}

Olahraga renang merupakan olahraga yang dilakukan diair dengan melakukan gerakan atau gaya tertentu diantaranya gaya kupu, gaya punggung, gaya dada dan gaya bebas. Dalam perlombaan renang tidak hanya empat gaya saja yang diperlombakan, namun dari empat gaya terdapat banyak nomor yang diperlombakan. Nomor perlombaan renang yang akan dicatat dalam rekor dunia pada kolam 50 meter baik laki-laki maupun perempuan diantaranya Gaya Bebas: 50 m, 100 m, 200 m, 400 m, 800 m dan 1500 m, Gaya Punggung: 50 m, 100 m, 200 m, Gaya Dada: 50 m, 100 m, 200 m, Gaya Kupu: 50 m, 100 m, 200 m, Gaya Ganti Individual: 200 m dan 400 m, Estafet Gaya Bebas: 4 x 50 m, 4 x 100 m, 4 x 200 m, Estafet Gaya Ganti: 4 x 50 m dan 4 x 100 m, Estafet Campuran: 4 x $50 \mathrm{~m}$ bebas dan 4 x $50 \mathrm{~m}$ gaya ganti (Sestiawan, 2017:22).

Perlombaan renang merupakan olahraga yang dituntut renang dengan kecepatan maksimal sehingga hasil akhirnya akan diambil catatan waktu tercepat yang akan jadi pemenangnya. Untuk mencapai catatan waktu tercepat, perenang tidak hanya mengandalkan berenang yang cepat dalam renang gaya tertentu saja namun harus juga melakukan reaksi yang cepat dan lompatan yang jauh ketika start, tahan dan cepat ketika underwater. Permasalahan akan muncul ketika perenang tidak mampu melakukan reaksi yang cepat dan lompatan yang jauh ketika start, tidak tahan dan tidak cepat ketika underwater, sehingga hasil akhir kecepatan renang di nomor tertentu menjadi tidak maksimal.

Hal tersebut penulis temukan ketika mengamati atlet renang GAC (Galunggung Aquatic Club) yang berlatih di kolam renang Dadaha Tasikmalaya, penulis yang juga sebagai pelatih GAC menemukan kelemahan atlet GAC yang kurang tahan dan kurang cepat ketika melakukan underwater pada saat renang gaya kupu-kupu. Ada perenang yang tahan underwater sejauh 15 meter namun lambat, ada juga perenang yang tidak mampu underwater sejauh 15 meter. Kenapa harus 15 meter? karena dalam aturan FINA (Federation International De Natation), perenang hanya diperbolehkan melakukan underwater setelah start dan pembalikan dengan jarak 15 meter, setelah jarak 15 meter kepala harus memecah permukaan air (FINA, 2017:12).

Permasalahan tersebut muncul, membuat penulis mencari cara untuk dapat memecahkan masalah dengan memanfaatkan permainan tradisional yang menarik dan menyenangkan sehingga atlet yang melakukan permainan tersebut tidak merasa terbebani melainkan semangat melakukannya karena sifatnya bermain namun diharapkan dapat meningkatkan kemampuan atlet. Selain itu penulis juga ingin mengangkat kearifan lokal yang dimiliki oleh salah satu daerah di Indonesia yang dapat dimanfaatkan dalam latihan untuk meningkatkan performa atlet khususnya pada cabang olahraga renang.

Permainan tradisional identik dengan permainan masa kecil ketika bermain, dengan permainan tradisional bermain menjadi lebih menyenangkan karena tidak merasa tertekan oleh aturan atau perintah walaupun pada saat melakukannya merasa lelah. Ketika melakukan permainan tradisional pelakunya tidak menyadari bahwa banyak manfaat yang didapat ketika melakukan permainan tersebut seperti memperoleh pembendaharaan gerak, meningkatkan kondisi fisik, mendapatkan nilai-nilai positif ketika bermain seperti kejujuran, kerjasama, kepemimpinan, disiplin dan lain-lain. Hal inilah yang nantinya akan menjadi bekal anak untuk kemudian menjadi kemampuan dan karakter yang melekat sampai mereka dewasa (Ishak, 2015).

Permainan tradisional yang penulis teliti dalam penelitian ini yaitu permainan tradisional elengan. Permainan tradisional elengan merupakan permainan tradisional yang dilakukan diair. Elengan merupakan permainan tradisional yang pernah dilakukan penulis sewaktu kecil di sungai. Elengan adalah permainan yang dilakukan di air oleh suatu kelompok yang sifatnya berkejar-kejaran dengan melakukan berenang. Seseorang yang mengejar berusaha menangkap kelompok yang dikejar dengan cara memegang kepalanya karena jika memegang bagian tubuh lain dianggap tidak tertangkap. Kelompok yang dikejar berusaha meloloskan diri dengan cara menyelam (underwater), karena dengan underwater kelompok yang dikejar tidak dianggap tertangkap ketika kepalanya dipegang di dalam air. Perenang yang dikejar akan berusaha menghindar dengan cara underwater sehingga peserta permainan elengan ini secara tidak langsung dipaksa untuk melakukan underwater dengan jauh dan cepat, secara tidak sadar pula underwater peserta elengan sedang dilatih.

Permainan tradisional elengan yang penulis lakukan sewaktu kecil dilakukan di sungai yang berarus deras, permainan ini dilakukan untuk mengisi waktu luang ketika kita bermain dengan mandi di sungai (ngebak). Ngebak biasa kita lakukan hampir setiap hari, setiap kita ngebak pasti melakukan permainan elengan. Hasilnya baik saya maupun teman-teman yang lain mampu melakukan menyelam (underwater) 25-50 meter dengan cepat.

Permainan tradisional elengan ini akan penulis jadikan sebuah metode latihan yang akan diterapkan secara terprogram dalam olahraga renang terutama untuk melatih underwater. Metode latihan merupakan suatu cara yang telah disiapkan sesuai kebutuhan berdasarkan ilmu tertentu, diterapkan secara terprogram untuk dapat meningkatkan kemampuan seseorang (Adhi et al., 2017). Untuk menjadikan permainan tradisional elengan menjadi sebuah metode latihan, peneliti memodifikasi tempat permainannya dari kolam besar sampai kolam yang

Dipublikasikan Oleh :

UPT Publikasi dan Pengelolaan Jurnal

Universitas Islam Kalimantan Muhammad Arsyad Al Banjari Banjarmasin 
kecil, waktu pelaksanaan permainan yang semakin hari semakin lama untuk mencapai sifat overload dan memberikan variasi dalam latihan.

Permainan tradisional elengan dilakukan untuk meningkatkan kondisi fisik agar dapat menunjang terhadap pelaksanaan program dan pencapaian prestasi. Kondisi fisik berperan penting terhadap pelaksanaan program latihan atlet, maka dari itu program latihan haruslah direncanakan secara matang, dilakukan dengan sungguh sungguh secara bertahap, agar dapat meningkatkan kesegaran jasmani dan kemampuan fungsi sistem tubuh seingga atlet memungkinkan untuk dapat meraih prestasi yang lebih baik (Harsono, 2018:3). Salah satunya kondis fisik yang dilatih ketika melakukan permainan tradisional elengan yaitu kecepatan underwater. Kecepatan adalah kemampuan untuk melakukan gerakan yang sejenis dengan cepat atau kemampuan menempuh suatuh jarak tertentu dengan waktu yang sesingkat-singkatnya (Harsono, 2018b:145).

Pada olahraga renang misalnya, seorang atlet renang harus melakukasn gerakan-gerakan yang sejenis dengan cepat dari mulai gerakan kaki, gerakan tangan, sehingga membentuk laju berenang yang cepat, termasuk underwater dalam renang gaya kupu-kupu.

Gaya kupu-kupu merupakan gaya renang yang gerakannya menyerupai ikan lumba-lumba berenang, dilihat dari gerakan tubuhnya yang naik turun dari mulai kepala, pinggul, dan kaki. Namun kenapa gaya renang yang mirip ikan lumba-lumba berenang ini malah dinamai gaya kupu-kupu? Mungkin karena pada saat seseorang melakukan berenang gaya kupu-kupu tangan perenang melebar lurus ke samping seperti kepakan sayap kupukupu.

Berdasarkan pengalaman penulis dan cerita dari yang pernah maupun yang sering melakukan berenang gaya kupu-kupu, gaya kupu-kupu dalam olahraga renang merupakan gaya yang paling berat dan melelahkan untuk melakukannya dibandingkan dengan gaya yang lain seperti gaya punggung, gaya dada, dan gaya bebas karena selain berat melawan resistance, kedua tangan perenang harus mengayuh untuk mengangkat dan mendorong badan ke depan agar dapat melakukan pengambilan napas dan melakukan luncuran. Maka dari itu dibutuhkan kondisi fisik yang mumpuni dari mulai daya tahan, stamina, fleksibilitas, kekuatan, power, koordinasi, kecepata dan kondisi fisik lainnya.

Lengan diibaratkan sebagai alat mendayung untuk mendorong air sehingga menghasil daya dorong untuk menggerakan badan meluncur ke depan. Dalam berenang gaya kupu-kupu lengan merupakan alat yang paling dominan menghasilkan daya dorong, selain dilihat dari fungsi geraknya sebagai alat untuk mendayung. Selanjutnya menurut Crowley et al., (2017) kekuatan tubuh bagian atas berperan penting terhadap daya dorong dan kecepatan renang. Selanjutnya hasil penelitian juga menunjukan bahwa korelasi kuat $(r=0,93)$ antara kekuatan tubuh bagian atas dan kinerja renang (Crowley et al., 2017).

Selain mengendalkan fisik teknik juga harus dilakukan dengan benar untuk dapat berenang lebih efesien, maksudnya tenaga yang dikeluarkan lebih sedikit namun hasilnya dapat dimaksimalkan (Strzała et al., 2017).

Sesuai dengan permasalahan yang melatar belakangi penelitian ini, penulis mencoba memberikan solusi dengan melakukan penelitian "Pengaruh Permainan Tradisional Elengan Terhadap Kecepatan Underwater Rengan Gaya Kupu-Kupu”, pada klub renang GAC (Galunggung Aquatic Club) kelompok umur 5-4 di kolam renang Sukapura Dadaha Tasikmalaya.

Penelitian ini terdapat beberapa kesamaan variabel dengan penelitian sebelumnya, penelitian-penelitian tersebut memiliki tujuan dan menghasilkan solusi yang berbeda-beda sesuai masalah yang dihadapi. Berikut ini beberapa penelitian yang membahas mengenai permainan tradisional.

Kusumawati (2017) Pengaruh permainan Tradisional Terhadap Peningkatan Kemampuan Gerak Dasar Siswa Sekolah Dasar Kelas Bawah. Temuan penelitian ini adalah sebagai berikut: Hasil penelitian menunjukan pengaruh latihan permainan tradisional terhadap hasil gerak dasar lari lompat lempar siswa kelas 2 SDN 2 Blitarejo Gadingrejo Pringsewu Lampung Tahun Pelajaran 2015/2016.

Ishak (2015) Latihan Olahraga Dalam Permainan Tradisional. Temuan penelitian ini sebagai berikut : Dalam penelitian banyak nilai-nilai terkandung didalamnya seperti kejujuran, kerjasama, kepemimpinan, disiplin, dan lain sebagainya. Nilai-nilai karakter inilah yang sangat dibutuhkan ileh anak, untuk kemudian menjadi karakter yang melekat sampai mereka dewasa. Disamping itu manfaat lain yang tidak kalah penting dari permainan tradisional adalah untuk mengembangkan kemampuan fisik anak. Permainan tradisional yang dilakukan oleh anak secara langsung berpengaruh terhadap keterampilan motorik anak. Secara tidak langsung anak sudah melakukan aktivitas latihan olahraga yang bersumber dari permainan tradisional.

Saputra \& Ekawati (2017) Permainan Tradisional Sebagai Upaya Meningkatkan Kemampuan Dasar Anak. Temuan penelitian ini sebagai berikut: Hasil penelitian menunjukkan bahwa ada tiga belas desain permainan tradisional yang sesuai dengan anak usia dini, dan tiga di antaranya memerlukan bimbingan dari orang dewasa/orang tua saat dalam pelakukan permainan. Keterampilan dasar yang dikembangkan oleh permainan

Dipublikasikan Oleh :

UPT Publikasi dan Pengelolaan Jurnal

Universitas Islam Kalimantan Muhammad Arsyad Al Banjari Banjarmasin 
tradisional adalah kecerdasan kinestetik, kecerdasan linguistik, kecerdasan logis matematis, kecerdasan spasial visual, kecerdasan musik, kecerdasan alami, kecerdasan alami, kecerdasan antarpribadi, kecerdasan intrapersonal, kecerdasan intelektual, kecerdasan spiritual.

Deritani et al., (2014) Pengembangan Permainan Tradisional Ekar Mix Dalam Pembelajaran Penjasorkes. Temuan penelitian ini sebagai berikut: Kesimpulan, penembangan permainan tradisional Ekar Mix untuk pembelajaran penjasorkes di SD menghasilkan produk efektif meningkatkan kebugaran jasmani siswa. Disaarankan bagi guru penjasorkes menggunakan permainan tradisional Ekar Mix sebagai bahan ajar dalam pembelajaran penasorkes.

Kajian literatur (state of the art) yang dicantumkan di atas menggambarkan banyaknya penelitian khususnya yang mengkaji permainan tradisional. Walaupun masih belum menemukan permainan tradisional yang dihubungkan atau mempengaruhi belajar renang dan peningkatan prestasi renang. Namun dengan adanya contoh penelitian yang menghubungkan permainan tradisional dengan peningkatan belajar gerak, peningkatan kondisi fisik, pemberian nilai positif dalam pendidikan melalui aktivitas fisik, itu merupakan dasar yang memperkuat penelitian yang telah peneliti lakukan tentang permainan tradisional yang mempengaruhi kecepatan underwater dalam cabang olahraga renang. Hal tersebut mengisyaratkan bahwa penelitian yang penulis lakukan merupakan penelitian yang baru yang dapat menambah khasanah penelitian olahraga khususnya dalam olahraga permainan tradisional.

\section{METODE}

Penelitian ini dilakukan di kolam renang Dadaha Tasikmalaya. Tes awal dilakukan pada tanggal 01-07-2019 dan tes akhir dilakukan pada tanggal 09-08-2019. Bahan instrumen yang digunakan berupa stopwatch, pluit, alat tulis, dan kolam renang.

Teknik pengumpulan data dalam penelitian ini adalah menggunakan tes kecepatan underwater dengan jarak $15 \mathrm{~m}$. Kenapa harus 15 meter? karena dalam aturan FINA, perenang hanya diperbolehkan melakukan underwater setelah start dan pembalikan dengan jarak 15 meter, setelah jarak 15 meter kepala harus memecah permukaan air (FINA, 2017:12). Selain itu tes $15 \mathrm{~m}$ ini didasari dari tes kecepatan menurut Johnson dan Nelson (Nurhasan \& Narlan, 2017:129) menerangkan bahwa kecepatan umumnya diukur dengan lari menempuh jarak pendek. Jarak yang melebihi 100 yard biasanya dianjurkan karena oleh faktor daya tahan. Sedangkan menurut Eckert (Nurhasan, 2017:129) menjelaskan tentang pengukuran kecepatan pada umumnya adalah lari lurus jarak minimal 30 yard dan maksimal 100 yard. Berdasarkan tes kecepatan tersebut penulis melakukan tes underwater 15 meter berdasarkan aturan dan merujuk pada tes kecepatan lari, bahwa tes kecepatan tidak lebih dari 30/100 yard.

Metode penelitian dalam penelitian ini menggunakan metode eksperimen dengan menggunakan model onegroup pretest-postest design.

\section{$\mathrm{O}_{1} \mathrm{XO}_{2}$}

Gambar 1. Rancangan Penelitian Nonequivalent Control Group Design (Sugiyono, 2017:79)

Menggunakan metode penelitian ekperimen karna ingin mengetahui hasil dari sebuah perlakuan dan menggunakan model one-group pretest-postest design dengan harapan hasil perlakuan dapat diketahui lebih akurat karena dapat membandingkan hasil sebelum diberikan perlakuan dengan setelah diberikan perlakuan.

Penelitian ini menggunakan populasi dan sampel kepada atlet Galunggung Aquatic Club kelompok umur 4 (KU 4) dan Kelompok Umur 5 (KU 5) sebanyak 20 atlet. Penulis mengambil populasi KU 4 dan KU 5 karena KU tersebut dilihat yang masih lemah, baik dalam keterampilan dan daya tahan melakukan underwater. Metode pengambilan sampel yang penulis gunakan dengan cara total sampling, yaitu dengan cara melibatkan semua populasi KU 4 dan KU 5 yang berlatih di Galunggung Aquatic Club.

Teknik menganalisis data pada penelitian ini yang penulis gunakan adalah teknik analisis statistik t-test sampel tidak berpasangan. Dengan sistematika sebagai berikut:

1. Menentukan rata-rata dan standar deviasi

2. Menguji validitas dan reliabilitas instrument

3. Uji normalitas dan homogenitas data

4. Uji t sampel

Dipublikasikan Oleh :

UPT Publikasi dan Pengelolaan Jurnal

Universitas Islam Kalimantan Muhammad Arsyad Al Banjari Banjarmasin 


\section{HASIL DAN PEMBAHASAN}

Pengujian hipotesis ini dilakukan untuk memberikan apakah hipotesis yang penulis ajukan dalam penelitian ini diterima atau ditolak. Sehubungan dengan data dalam penelitian ini berdistribusi normal dan homogen, maka statistik yang digunakan adalah parametrik. Dengan demikian untuk keperluan pengujian hipotesis penelitian ditempuh analisis statistik dengan menggunakan uji kesamaan dua rata-rata uji satu pihak menggunakan uji t.

Adapun hasil pengujian hipotesis penelitian ini penulis sajikan pada tabel berikut ini.

Tabel 1. Hasil Analisis Data

\begin{tabular}{|l|c|c|l|}
\hline Kelompok Latihan & Nilai t hitung & Nilai t tabel Pada $(\boldsymbol{\alpha}=\mathbf{0 , 0 5})$ dan dk=n' & Kesimpulan \\
\hline $\left.\begin{array}{l}\text { - Tes Awal } \\
\text { - Tes Akhir }\end{array}\right\}$ & 3,36 & 2,10 & Terdapat Pengaruh \\
\hline
\end{tabular}

Tabel di atas menunjukan bahwa nilai t'hitung sebesar 3,36 ternyata lebih besar dari t'tabel pada $\boldsymbol{\alpha}=0,05$ dan berada di daerah penerimaan hipotesis, sehingga hipotesis nol (Ho) ditolak dan hipotesis kerja diterima. Hal ini menunjukan bahwa permainan tradisional elengan dapat berpengaruh terhadap kecepatan underwater renang gaya kupu-kupu, yang diterapkan pada klub renang GAC (Galunggung Aquatic Club) di kolam renang Sukapura, Dadaha Tasikmalaya.

Hipotesis tersebut hasilnya terbukti dan dapat diterima. Hal ini karena adanya pengaruh permainan tradisional elengan yang terprogram, karena permainan tradisional elengan ini secara tidak langsung menuntut peserta permainan untuk menghindari lawan dengan cara melakukan underwater sehingga peserta terbiasa melakukan underwater berulan-ulang, menjadikan atlet tahan melakukan underwater dan secara tidak langsung dipaksa cepat untuk melakukanya untuk menghindari lawan. Maka dari itu atlet yang melakukan permainan tradisional elengan secara terprogram, mereka sama dengan sedang melakukan latihan karena latihan merupakan aktivitas yang dilakukan dengan pengulangan dan penambahan beban yang sistematis (Harsono, 2018:50).

Dalam penelitian ini elengan dilakukan secara berulang-ulang selama 16 kali pertemuan, waktu pelaksanaan semakin bertambah ditandai dengan penambahan set atau jumlah melakukan permainannya, intensitas latihan ditambah ditandai dengan variasi luas kolam yang semakin kecil, karena semakin kecil pergerakan akan semakin sempit dan akan semakin sering melakukan underwater. Permainan tradisional elengan dapat meningkat salah satu pemicunya dilakukan melawan manusia yang menyebabkan permainan ini menjadi kompetitif yang memaksa seseorang memaksimalkan kemampuannya. Hal ini diperkuat oleh hasil penelitian Gorsic et al., (2019) yang membandingkan 4 jenis lawan dalam permainan kompetitif:

1. Melawan computer sederhana

2. Melawan computer mirip manusia

3. Melawan masnusia

4. Melawan computer sederhana disertai oleh manusia

Hasilnya melawan manusia lebih banyak dipilih yaitu 14 dari 16 peserta dan melawan manusia lebih banyak diminati / disenangi selain itu melawan manusia mendapatkan intensitas paling tinggi dibandingkan permainan yang lainnya.

Selain penelitian diatas, penelitian permainan tradisional elengan juga diperkuat oleh penelitian Nurdiansyah (2018) yang meneliti tentang permainan tradisional hadang terhadap kelincahan. Permainan hadang tersebut diberikan dengan intensitas latihan yang tinggi dan penambahan beban latihan yang tepat, sehingga hasilnya permainan tradisional hadang berpengaruh terhadap agility dengan taraf kepercayaan (a) 0,05 . Penelitian tersebut meberikan informasi bahwa penelitian tradisional dapat meningkatkan kondisi fisik jika dilakukan dengan intensitas dan penambahan beban yang tepat dari pelakunya

\section{PENUTUP}

Permainan tradisional merupakan aktivitas bermain yang biasa dilakukan anak-anak untuk mengisi waktu luang dan tercipta hasil ide kreatif lingkungan bermain disuatu daerah tertentu. Permainan tradisional sangat kaya akan nilai-nilai kebudayaan dan nilai-nilai positif, karna mengajarkan mereka kelompok bermainnya untuk taat aturan, jujur, saling menghargai antar teman, berdemokrasi antar sesama, selain itu mereka juga berkreasi memunculkan idenya dalam bermain sesuai dengan adat budaya kebiasaan yang ada disekelilingnya sehingga manfaatnya dapat mengangkat kearifan lokal di suatu daerah tertentu. 
Permainan tradisional tidaklah hanya sekedar permainan untuk kesenangan semata, namun secara tidak sadar banyak sekali pembendaharaan gerak yang kita kenali hasil dari bermain dalam permainan tradisional, banyak juga sumbangsih kondisi fisik yang tumbuh dalam tubuh kita hasil dari bermain dalam permainan tradisional. Seperti halnya permainan tradisional elengan yang diungkap dalam penelitian ini merupakan permainan yang mengenalkan gerak menyelam di bawah pemukaan air dan dengan permainan tersebut, pelaku permainan ini memiliki daya tahan dan kecepatan untuk melakukan underwater.

Permainan tradisional elengan yang diungkap dalam penelitian ini menambah daftar penelitian yang membuktikan bahwa permainan tradisional dapat memberikan pengaruh yang positif salah satunya yang diungkap dalam penelitian ini berpengaruh perhadap kecepatan underwater dalam renang gaya kupu-kupu.

\section{REFERENSI}

Adhi, B. P., Sugiharto, \& Soenyoto, T. (2017). Pengaruh metode latihan dan kekuatan otot tungkai terhadap power otot tungkai. Journal of Physical Education and Sports, 6 (1), 7-13

Crowley, E., Harrison, A. J., \& Lyons, M. (2017). The impact of resistance training on swimming performance. Journal Sports Medicine, 47 (11), 2285-2307

Nurdiansyah, D. (2018). Pengaruh permainan tradisional hadang terhadap agility. Jurnal Olahraga, 3 (2), 1-7.

Fina. (2017). "Fina Swimming Rules 2017-2021". Part III, 1-20. Diakses dari: https://www.fina.org/sites/default/files/2017_2021_swimming_12092017_ok_0.pdf

Harsono. (2018a). Kepelatihan Olahraga (Edisi ke-3). Bandung: PT Remaja Rosdakarya.

Harsono. (2018b). Latihan Kondisi Fisik. Bandung: PT Remaja Rosdakarya.

Ishak, M. (2015). Latihan olahraga dalam permainan tradisional. Jurnal Ilmu Keolahragaan, 14 (2), $42-48$.

Kusumawati, O. (2017). Pengaruh permainan tradisional terhadap peningkatan kemampuan gerak dasar siswa sekolah dasar kelas bawah. Jurnal Pendidikan Dan Pembelajaran Dasar, 04 (2), 124-142.

Gorsic, M., Hlucny, S. D., \& Novak, D. (2019). Effects of different opponent types on motivation and exercise intensity in a competitive arm exercise game. Games for Health Journal, 09 (1), 1-6.

Deritani, N. L., Soegiyanto, \& Sulaiman. (2014). Pengembangan permainan tradisional ekar mix dalam pembelajaran penjasorkes. Journal Of Physical Education And Sports, 3 (1). 41-45

Nurhasan, \& Narlan. A. (2017). Tes dan Pengukuran Penddikan Olahraga. Lembaga Penerbit Pendidikan Jasmani Fakultas Keguruan dan Ilmu Pendidikan Universitas Siliwangi.

Saputra, N. E., \& Ekawati, Y. N. (2017). Permainan tradisional sebagai upaya meningkatkan kemampuan dasar anak. Jurnal Psikologi Jambi, 2 (2), 48-53.

Setiawan, T. T. (2017). Swimming Rules ( Sw ) Perubahan Berdasar Memorandum 2015. (Part III.). (FINA).

Strzała, M., Stanula, A., Krȩzałek, P., Ostrowski, A., Kaca, M., \& Głąb, G. (2017). Butterfly Sprint Swimming Technique, Analysis of Somatic and Spatial-Temporal Coordination Variables. Journal of Human Kinetics, $60(1), 51-62$.

Sugiyono. (2017). Metode Penelitian Pendidikan (Pendekatan Kuantitatif, Kualitatif, dan R\&D) (Edisi ke-26). Bandung: Alfabeta.

Dipublikasikan Oleh :

UPT Publikasi dan Pengelolaan Jurnal

Universitas Islam Kalimantan Muhammad Arsyad Al Banjari Banjarmasin 